\title{
Research on the Path of Integration of Innovation and Entrepreneurship Education and Professional Education in Applied Universities
}

\author{
Yajuan Sun \\ Xijing University \\ Xi'an, Shaanxi, China \\ Email: 723240327@qq.com
}

\begin{abstract}
The integration of innovation and entrepreneurship education and professional education is an inevitable requirement for the scientific development of innovation and entrepreneurship in Colleges and universities. It is also the inevitable trend of the reform of talent training mode in Colleges and universities. Based on the investigation of the current situation of the integration of innovative entrepreneurship education and professional education in Applied Colleges and universities, on the basis of analyzing the existing problems, this paper puts forward some suggestions to promote the transformation and development of Applied Colleges and universities, create the campus culture of the characteristic innovation and entrepreneurship education, and integrate the internal and external resources of the University.
\end{abstract}

Keywords: Applied university, Innovation and Entrepreneurship Education, Professional education, Integration Path

\section{INTRODUCTION}

The combination of innovation and entrepreneurship education and professional education is one of the outstanding problems in our university's innovation and entrepreneurship education. Through the game analysis between the stakeholders, Li-na Song [1] believes that the concept system, the mode of running a school and the cultural construction are the important factors affecting the integration of entrepreneurial education and professional education. Bo Liu [2] believes that the separation of innovation and entrepreneurship education from professional education is mainly manifested in three aspects: Students' consciousness, teachers and curriculum. Applied universities mainly focus on cultivating high quality and applied talents adapting to the economic and social development, emphasizing practical, practical and technical knowledge, which coincides with the core ideas of innovation and entrepreneurship education. The scientific and deep development of innovative entrepreneurship education in Applied Colleges and universities should be based on the relationship between the two elements of scientific innovation and entrepreneurship education and professional education. Both should actively seek organic integration, promote each other and develop together.

\author{
II. THE PRACTICAL SIGNIFICANCE OF THE \\ INTEGRATION AND DEVELOPMENT OF \\ INNOVATION AND ENTREPRENEURSHIP \\ EDUCATION AND PROFESSIONAL EDUCATION
}

\section{A. Leading the Transformation of Applied Universities}

At present, there are two extremes in the transformation process of Applied Colleges and Universities: overemphasizing the ability of practice, ignoring the cultivation of the individual quality of the students, or overrelying on professional learning, weakening the guidance of the students' creative ability. The introduction of innovation and entrepreneurship education in higher education has led the transformation of universities to a large extent. [3]. The essence of innovation and entrepreneurship education is to cultivate innovative talents, and cultivate individuals with innovative consciousness and entrepreneurial ability on the basis of professional education. Entrepreneurship is a very direct and effective way to obtain employment. The purpose of innovation and entrepreneurship is to promote entrepreneurship through innovation and promote employment through entrepreneurship. This aspect is also one of the important problems facing the transformation of universities. Innovation and entrepreneurship education is the starting point for the transformation of applied universities, and the combination of professional education is a specific means of implementation.

\section{B. Promoting the Reform of Higher Education}

In the course of the development of higher education, professional education, which is imparted to students' knowledge and skills, has been the main task, the continuous enrichment and accumulation of professional education, the overall system has been more perfect. However, under the current social and economic development and the requirements of higher education, the educational concept, teaching mode, curriculum system, assessment model and teachers of professional education are far from adapting to the demand for talents in the market, and can not meet the needs of College Students' innovation and entrepreneurship. The implementation of innovation and entrepreneurship education, the students' innovative spirit and entrepreneurial ability in the main content of talent training, is the expansion of the field of talent training outside the professional education, is the adaptation of the all-round changes in the development of the times. This requires education and teaching activities not only to focus on professional education activities, but also to cultivate students' innovative ability and other qualities.

\section{Train of Thought on Promoting Innovative Applied}




\section{Talents}

Strengthen quality education and innovation on the basis of professional training. In recent years, colleges and universities have actively explored the training mode of innovative applied talents through various ways, such as deepening education reform, improving the level of teachers and building resources platform. The starting point and the foothold of the innovation and entrepreneurship education is to combine the professional education to promote the all-round development of the students, stimulate the innovative spirit of independent thinking, improve the practical ability of the problem solving and improve the comprehensive quality of the students. This is consistent with the training characteristics of innovative applied talents. The process of deepening and realizing the innovation and entrepreneurship education is actually the exploration and promotion of the train of thought for innovative applied talents. The deep integration of innovation and entrepreneurship education in professional education is one of the important measures to cultivate innovative applied talents.

\section{PROBLEMS IN THE INTEGRATION AND DEVELOPMENT OF INNOVATION, ENTREPRENEURSHIP AND PROFESSIONAL EDUCATION}

\section{A. The Lack of Professional Education in the Implementation of Innovative and Entrepreneurial Education}

With the increasing attention of the state to the innovation and entrepreneurship education of college students, colleges and universities have spared no effort in the development of innovative and entrepreneurial courses and teaching materials, the construction of the base of entrepreneurial practice, the formation of students' practical guidance team, and the establishment of the fund for college students. But the starting point of innovation and entrepreneurship is only to increase the related courses of innovation and entrepreneurship in general education or compulsory courses and elective courses, and still maintain the original curriculum system, teacher allocation and teaching methods in the learning stage of professional courses, and do not combine innovation and entrepreneurship education with professional education. Some colleges and universities promote students' innovation by increasing the competition of science and technology, encouraging students to participate in "Challenge Cup" competition and "Youth" competition, but this innovation is completed in the case of training out of professional courses and professional talents. Professional education and innovation and entrepreneurship education are still two lines, which do not combine the two very well, resulting in the lack of professional education in the process of innovation and entrepreneurship education.

\section{B. The Deviation of Innovation and Entrepreneurship Education in Professional Education}

The first is that the curriculum system of professional teaching does not change, but it only adds innovation and entrepreneurship education courses such as "entrepreneurship management" and "creative thinking", and does not attach importance to the connection between the related courses and the professional courses of innovation and entrepreneurship, without the construction of the curriculum system, which results in the students studying several courses in the learning stage of the professional course. The harvest is not big; two is the idea of adding innovative and entrepreneurial education to professional courses, but the input method of this concept is only an example of enterprise innovation or new enterprise creation in the course. This example teaching does not bring too much change to the classroom, nor does it bring profound ideological changes at the school level. However, it is difficult to translate into entrepreneurial practice under the course of class; three is to increase the input of innovation and entrepreneurship education in professional education, including the thinking mode, the angle of analysis and the innovation of solving the problems, but it does not connect with the practice links under the students' course, and does not really extend the creation of new entrepreneurship education to the professional education. These links lead to limited students' innovative ability and no corresponding enhancement of talent value.

\section{THE INTEGRATION PATH OF INNOVATION AND ENTREPRENEURSHIP EDUCATION AND PROFESSIONAL EDUCATION}

\section{A. Promoting the Transformation of Applied Universities} by Means of Innovation and Entrepreneurship Education

At present, with the gradual promotion of the comprehensive reform of higher education, all colleges and universities are in the new stage of transformation and upgrading, and the existing applied universities should carry out more exploration in the reform of talent training mode and go ahead. The leaders of colleges and universities should put the innovation and entrepreneurship education in the innovative talent training mode and promote the new height of the University's transformation and upgrading, combined with the characteristics and advantages of running a school, the overall design, and the overall promotion. At this stage, we should actively seek an organic combination of entrepreneurship education and professional education, and embody the importance of innovation and entrepreneurship education in training programs, introducing and training excellent teachers, supporting funds budgets and setting up work institutions. In order to set up a perfect training program, the university should adhere to the basic guidance of Lide tree people, clear the goal of innovation and entrepreneurship education, and highlight the importance of innovation and entrepreneurship education. It is necessary to make the innovation and entrepreneurship education through the whole process of university talent training through the clear innovation of the responsibilities of the education sector, the creation of innovative and entrepreneurial education courses and the setting of a fixed innovation and 
entrepreneurship education credit.

\section{B. Create a Unique Innovation and Entrepreneurship Education Campus Culture}

In the stage of popularization, there are many colleges and universities. It is impossible for universities to go all the way to traditional elite universities, and should be close to the reality of society [4].It is also based on this understanding that more and more applied universities have gradually changed the concept of development, from a one-sided pursuit of a big, to an outstanding unique advantage of running a school, and take a characteristic development path. In the future, nearly half of the colleges and universities will turn to applied universities. Under this background, the applied universities should highlight their own advantages, combine their own disciplines and scientific research characteristics to carry out innovative and entrepreneurial education, combine professional learning with innovation and entrepreneurship, and form a situation of mutual promotion and benign interaction. From the current situation of the integration of innovation and entrepreneurship education and professional education, the urgent task is to set up an education model with the core curriculum as the center and the combined curriculum. We should improve the establishment of collaborative innovation institutions and explore the working mode and mechanism combined with the actual situation of schools.

C. Integrating Resources inside and outside School to Promote the Development of Innovation and Entrepreneurship Education

From the perspective of resource integration, application-oriented universities should actively build two resource integration platforms inside and outside school [5]. From the school level, we can explore the construction of innovation and entrepreneurship education guidance institutions, each department can also establish their own innovation and entrepreneurship education center or corresponding organizations. At the same time, the innovation and entrepreneurship education is a special form of education which is different from the professional education. It has a strong dependence on external conditions. Besides the active integration of the internal resources, we should pay more attention to expanding the resources outside the school.

\section{REFERENCES}

[1] Li-na Song. Based on game theory, the dilemma and Countermeasures of entrepreneurship education and professional education integration [J]. education review, 2017 (10): 79-83.

[2] Bo Liu. Research on the coupling mechanism between innovation and entrepreneurship in universities and colleges. [J]. adult education in China, 2017 (12): 68-71.

[3] Li-xia Gong. Thinking on the reform of undergraduate education in Applied Colleges and Universities -- Based on the combination of innovative entrepreneurship education and professional education, the Journal of $[\mathrm{J}]$. National Institute of education administration, 2011 (09): 43-46+12.

[4] Mao-yuan Pan. What is applied undergraduate? [J]. higher education exploration, 2010 (01): 10-11.

[5] Yu-wei Liu, Jiang-yi Mao. Analysis of the integration of innovation, entrepreneurship education and professional education. [J]. Beijing Education (Higher Education), 2017 (02): 64-67. 